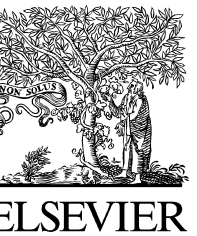

ORIGINAL ARTICLE

\title{
Relationship between dairy product intake during pregnancy and neonatal and maternal outcomes among Portuguese women
}

\author{
Sandra Abreu ${ }^{1,2, *}$, Paula C. Santos ${ }^{1,3}$, Nuno Montenegro ${ }^{4}$, \\ Jorge Mota ${ }^{1}$
}

\author{
${ }^{1}$ Research Centre in Physical Activity, Health and Leisure, Faculty of Sport, \\ University of Porto, Portugal \\ ${ }^{2}$ Lusófona University of Porto, Faculty of Psychology, Education and Sport, Porto, \\ Portugal \\ ${ }^{3}$ Department of Physical Therapy, School of Health Technology of Porto, Polytechnic \\ Institute of Porto, Vila Nova de Gaia, Portugal \\ ${ }^{4}$ Department of Obstetrics \& Gynecology, São João Hospital Center, Medicine \\ Faculty-University of Porto, Portugal
}

Received 22 March 2016; received in revised form 28 June 2016; accepted 4 July 2016

\section{KEYWORDS}

Dairy product intake;

Pregnancy;

Neonatal outcomes;

Maternal outcomes

\begin{abstract}
Summary
Background: The role played by dairy product intake during pregnancy on neonatal outcomes has raised interest in the last few years. However, studies on this association remain scarce. Thus, the aim of this study was to determine the association between dairy product consumption during pregnancy and neonatal and maternal outcomes.

Methods: A prospective study was conducted with 98 pregnant women, aged 18-40, from the city of Porto, Portugal. Socio-demographic and lifestyle characteristics were assessed through a questionnaire. Dairy product consumption was assessed with a three-day food diary completed during the first and second trimesters. Postpartum medical records were examined for neonatal and maternal outcomes. Multivariate linear regression analyses were performed to assess the association between dairy intake and neonatal and maternal outcomes, adjusting for dietary variables and maternal characteristics.
\end{abstract}

* Corresponding author at: Faculty of Sport, University of Porto, Research Centre in Physical Activity, Health and Leisure, Rua Dr. Plácido Costa, 91 Porto, Porto 4200-450, Portugal. Tel.: +35 1936013645.

E-mail address: sandramrabreu@fade.up.pt (S. Abreu). 
Results: Compared to the first trimester pregnant women had higher energy intake and lower calcium, iodine and yogurt intake in the second trimester $(P<0.05)$. Total dairy and yogurt intake in the first trimester were positively associated with head circumference and placental weight (respectively $\beta=0.002, P=0.014, \beta=0.333, P=0.012$ ). Change in total dairy intake between the second and first trimester was negatively associated with maternal weight gain during pregnancy $(\beta=-0.007, P=0.020)$.

Conclusion: The findings of this study suggest that dairy product intake during pregnancy may have an effect on neonatal head circumference, placental weight, and gestational weight gain.

(c) 2016 Published by Elsevier Ltd on behalf of Asia Oceania Association for the Study of Obesity.

\section{Introduction}

Adequate maternal dietary intake ensures optimal nutritional needs to reach normal fetal growth and development. Therefore during pregnancy a balanced diet is recommended and should include plenty of complex carbohydrates, fruits and vegetables, moderate consumption of dairy products and protein, and limited amounts of low-nutrient, energy-dense foods [1]. Findings from the Auckland Birthweight Collaborative study have shown that women with higher scores on the "traditional" food pattern (characterised by fruit, vegetables, peas/maize, dairy food/yogurt and water) in early pregnancy were less likely to deliver a smallfor-gestational-age baby [2]. Accordingly, it has been described that improved maternal diet quality reduces the risk of fetal growth restriction [3] and preterm birth [4]. On the other hand, a recent randomised controlled efficacy trial showed that women's dietary micronutrient quality improvement, achieved through a daily snack providing additional green leafy vegetables, fruit, and milk, before conception and throughout pregnancy had no overall effect on birth weight [5].

Dairy products likely contribute to dietary quality [6] during pregnancy, as they are an important source of high-quality protein, magnesium, vitamin B12, zinc, riboflavin, and calcium. In the last decades, the effect of dairy products, especially milk, on health has raised public health awareness. Evidence from a recent non-systematic review reported that milk consumption during pregnancy increases gestational weight gain, placental, fetal, and birth weight and the authors suggest that dietary recommendations for milk consumption during pregnancy have to be re-evaluated [7].

Furthermore, although evidence from prospective studies is limited, it seems that moderate milk consumption relative to no or very low intake is positively associated with fetal growth and infant birth weight in healthy Western populations [8]. On the other hand, higher intake of total dairy products, cheese, yogurt, and calcium during pregnancy may reduce the risk of infantile allergic disorders [9]. Therefore, the effect of dairy product consumption during pregnancy on neonatal and maternal outcomes still remains unknown. Additionally, little is known about the effect of changes in dairy consumption during pregnancy as well as in isolate trimesters on neonatal and maternal outcomes.

The study of neonatal outcomes, such as birth weight, length, and head circumference, is important since these latter have been considered reliable indicators of fetal growth and health later in life [10-13]. Likewise, placental weight has been correlated to adverse outcomes such as stillbirth, neonatal death, low Apgar score, seizures, or respiratory morbidity [14]. Another important indicator is gestational weight gain, which has also been associated with women's future health and offspring health [15].

Thus, the study aims to determine the association between dairy product intake during pregnancy and neonatal and maternal outcomes.

\section{Materials and methods}

\section{Sampling}

Data for this study came from a prospective study of pregnant women attending outpatient obstetrics clinics at São João Hospital in Porto, Portugal. Women were invited to participate when they came in for their first ultrasound evaluation screening. The recruitment was made consecutively from July 2010 to May 2012. From those who agreed to participate, data were collected in the first trimester between the tenth and twelfth weeks of gestation (at the time of baseline assessment), in the second trimester between the twentieth and twenty-second weeks (at the time of the second ultrasound) and again in the immediate 
post-partum (24-48 h after delivery). Details on the study design and sampling strategy are reported elsewhere [16].

A total of 137 pregnant women were invited to participate in this study, and 133 (participation rate: $97.1 \%$ ) agreed to take part. Some of the 133 participants were subsequently excluded because of miscarriage $(n=1)$, no singleton pregnancy $(n=2)$, age higher than $40 \quad(n=1)$ and prematurity $(n=3)$. Furthermore, $30(22.6 \%)$ more participants were excluded because they did not have their delivery at São João Hospital nor provide their dietary data for each trimester. Thus, the final sample consisted of 98 women and their offspring. Women who were excluded from the study did not differ significantly from those who were included in terms of age, educational level, marital status (single/divorced and married/cohabitate), monthly income, pre-pregnancy body mass index (BMI), and parity $(P>0.05$, for all; data not shown).

All participants in this study were informed of its objectives and provided written informed consent. The study was approved by the Ethics Committee of the Hospital de São João (Reference No. 09988), and it was conducted in accordance with the World Medical Association's Helsinki Declaration for Human Studies.

\section{Neonatal and maternal outcomes}

Neonatal outcomes (birth weight, length, head circumference, and placental weight) and maternal outcomes (weight gain during pregnancy) were obtained from hospital records. The postpartum evaluation yielded data on birth weight (measured with an electronic scale to the nearest gram), length (measured with a pediatric stadiometer to the nearest centimetre), head circumference (measured with tape to the nearest millimetre) and placental weight (measured to the nearest gram). Weight gain during pregnancy corresponds to the difference between the self reported weight before pregnancy and the last weight recorded prior to delivery. Additionally, weight gain was classified as insufficient, adequate, and excessive, depending on whether women acquired weight below the recommended level, within the recommended level, or higher than the recommended level, respectively [17].

\section{Dietary intake}

Dietary intake was assessed by a three-day food diary that included two weekdays plus one weekend day, and was completed for each trimester. Oral and written instructions on how to complete the diary were given to the women by a trained nutritionist. Food portion sizes and beverages consumed were estimated using household measures (cups, glasses, spoons, slices, food wrappers, containers, etc.) as an aid in determining serving sizes. A description of each food and beverage consumed was recorded, including the method of preparation, the time it was eaten (to the nearest five minutes), location, and, if appropriate, the brand name of the product. The nutrient analysis was performed using the software Food Processor SQL (ESHA Research Inc., Salem, OR, US). This program relies on nutritional information from the United States that has been adapted for use with typical Portuguese foods and beverages. The nutrient and food means of the three days were used in the analysis.

The amounts of milk (whole, reduced-fat, and fat-free), yogurt, and cheese (including cottage and cream cheese) were presented in term of grams per day ( $\mathrm{g} /$ day). In this study, total dairy included milk, yogurt, and cheese.

Additionally, change in dairy product intake was computed as the difference between the second and first trimesters.

\section{Covariates}

To take into account the confounding effect of diet adequacy in our analyses, we used the Mediterranean diet score $[18,19]$ as an indicator of diet quality. This scale was computed according to Chatzi et al. [20] and is based on seven beneficial components (vegetables, legumes, fruits and nuts, cereals, fish, ratio of monounsaturated to saturated fatty acids and dairy products) and one detrimental component (meat and meat products). For the beneficial components a value of 1 was given to women with a consumption intake (g/day) equal to or above the median of the total sample and a value of zero for a daily intake below the median. For the detrimental components, a value of 1 was given to women with a consumption intake (g/day) below the median of the total sample and a value of zero for a daily intake equal to or above the median. The total Mediterranean diet score ranged between 0 (minimal adherence) to 8 (maximal adherence). Then, based on the total score, each woman was categorised into one of two groups for each trimester: low adherence ( $0-4$ points) or high adherence (5-8 points).

Height was measured to the nearest $\mathrm{mm}$ in bare or stocking feet, with participants standing upright against a Holtain Portable Stadiometer (Crymych, Pembrokeshire, UK). Pre-pregnancy BMI was estimated by using the ratio of weight $/$ height $^{2}$ $\left(\mathrm{kg} / \mathrm{m}^{2}\right)$ with a self-reported pre-pregnancy weight. 
Participants were classified as non-overweight, overweight, or obese according to World Health Organization criteria [21]. The underweight participants $(1 \%)$ were combined with the normal weight participants in the non-overweight category due to the fact that the former represented such a small proportion of the overall sample.

Gestational age at time of delivery was assessed based on last menstrual period and confirmed by first trimester ultrasound evaluation at 10-12 weeks.

Professional status was assessed via a selfreported questionnaire, and the participants were divided into three categories: employed (full- or part-time), unemployed, and student. Since only two subjects fell into the student category, they were pooled with the members of the employed category.

Each respondent was asked to estimate the total income (including pensions, allowances, and investments) received by all household members in the last month by using a single measure comprised of three narrowly-ranged income categories: $<500$ Euros, [500-1250[Euros and $\geq 1250$ Euros.

For the variable educational level, subjects were divided into three categories that reflected the organization of the Portuguese educational system: mandatory or less ( $\leq 9$ school years), secondary (10-12 school years), and college/university (>12 school years).

Concerning parity, women were considered primiparous if this was their first gestation and multiparous if they had at least one previous gestation.

For the variable supplementation, women were asked about their use of supplements (multivitamins, iron, calcium, magnesium and folic acid) in each trimester.

Regarding smoking habits, women were classified as smokers if they smoked at least one cigarette a day during each trimester. Women who smoked during the first trimester $(n=15)$ continued to smoke in the second trimester.

Height, educational level, and parity were assessed only at baseline.

\section{Statistical analysis}

Data are presented as mean \pm standard deviation (SD) unless otherwise stated. The KolmogorovSmirnov test was used to verify the variables' normality. Since cheese intake in both trimesters did not fit a normal distribution, it was natural log-transformed. An independent-samples $t$-test or one-way analysis of variance was performed to compare continuous variables between groups. A paired $t$-test was used to compare paired continuous variables.

Separate multivariate linear regression models were fitted to verify the relationships between each dairy product intake and neonatal and maternal outcome variables. Models were adjusted for energy intake ( $\mathrm{kcal} / \mathrm{day})$, weight gain during pregnancy $(\mathrm{kg})$, neonatal sex (reference - female), gestational age (weeks), and Mediterranean diet score. For maternal outcome, as weight gain is the dependent variable, pre-pregnancy BMI (reference - non-overweight) was introduced into the models. All variables were continuous in nature, other than neonatal sex and pre-pregnancy BMI.

All models were evaluated for normality of residuals and presence of residual higher than 3.3 SDs, and no statistical transformations of dependent variables were necessary. Multicollinearity was also checked using a variance inflation factor and correlation coefficient.

Linear regression analyses were done for the first and second trimesters and tracked any change in dairy product intake between these.

A power sample was done post hoc for multivariate linear models and for the relationship between total dairy (in first and second trimesters, and change during pregnancy), milk (in first and second trimesters, and change during pregnancy), yogurt (in second trimester), cheese (in first and second trimesters, and change during pregnancy) and placental weight; weight gain and total dairy (in first trimester), milk (in first trimester and change during pregnancy), yogurt and cheese (in first and second trimesters, and change during pregnancy), was lower than $80 \%$ ranging from 50 to $71 \%$.

Unstandardised regression coefficients $(\beta)$ were used to express the coefficients of the regression analyses. A $P$ value (two-tailed) of $<0.05$ was regarded as significant. Analyses were conducted with the statistical software package IBM SPSS Statistics Version 22.

\section{Results}

Dairy product intake during pregnancy according to maternal socio-demographic and lifestyle characteristics is described in Table 1. Pregnant women with higher educational level, and who were married had a higher intake of cheese in the first and second trimester than their counterparts $(P<0.05$, for all). In the second trimester, higher intake of cheese was found in women with higher income, and who were not overweight $(P<0.05$, for all). No significant differences were seen with total 
Table 1 Dairy product intake in the first and second trimesters according to maternal socio-demographic and lifestyle characteristics.

\begin{tabular}{lllll}
\hline Maternal characteristics & $n$ & $\%$ & First trimester & Second trimester
\end{tabular}

\begin{tabular}{|c|c|c|c|c|c|c|c|c|c|c|}
\hline & & & & & & & & & & \\
\hline & & & $\begin{array}{l}\text { Dairy }(\mathrm{g} / \mathrm{d}) \\
\text { Mean } \pm \mathrm{SD}\end{array}$ & Milk (g/d) & Yogurt (g/d) & Cheese $\S(g / d)$ & $\begin{array}{l}\text { Dairy }(\mathrm{g} / \mathrm{d}) \\
\text { Mean } \pm \text { SD }\end{array}$ & Milk (g/d) & Yogurt (g/d) & Cheese $^{\S}(\mathrm{g} / \mathrm{d})$ \\
\hline \multicolumn{10}{|l|}{$\overline{\text { Age }(\text { years) }}{ }^{\mathrm{a}}$} & \\
\hline $18-30$ & 46 & 46.9 & $352.0 \pm 165.9$ & $193.9 \pm 135.2$ & $143.4 \pm 114.2$ & $14.6 \pm 22.0$ & $346.9 \pm 164.1$ & $225.8 \pm 153.7$ & $105.1 \pm 79.2$ & $15.9 \pm 19.6$ \\
\hline $31-40$ & 52 & 53.1 & $348.4 \pm 134.9$ & $215.5 \pm 138.0$ & $115.4 \pm 82.6$ & $17.4 \pm 17.7$ & $335.0 \pm 136.3$ & $231.6 \pm 153.1$ & $82.6 \pm 72.0$ & $20.7 \pm 21.6$ \\
\hline \multicolumn{11}{|l|}{ Educational level $^{\mathrm{b}}$} \\
\hline Mandatory or less & 33 & 33.7 & $354.8 \pm 151.4$ & $197.6 \pm 135.3$ & $146.5 \pm 98.8$ & $10.8 \pm 11.3^{*}$ & $333.8 \pm 171.9$ & $218.6 \pm 172.8$ & $104.0 \pm 79.1$ & $11.2 \pm 13.2^{*}$ \\
\hline Secondary & 35 & 35.7 & $323.2 \pm 162.0$ & $185.7 \pm 141.9$ & $125.4 \pm 99.5$ & $12.0 \pm 15.5$ & $336.2 \pm 154.2$ & $221.5 \pm 153.1$ & $98.6 \pm 70.5$ & $16.1 \pm 17.5$ \\
\hline College/university & 30 & 30.6 & $376.2 \pm 130.7$ & $237.0 \pm 129.9$ & $112.6 \pm 99.4$ & $26.7 \pm 26.7$ & $353.2 \pm 117.9$ & $248.9 \pm 129.8$ & $75.0 \pm 77.7$ & $29.3 \pm 26.3$ \\
\hline \multicolumn{11}{|l|}{ Marital status } \\
\hline Single/divorced & 22 & 22.4 & $303.3 \pm 175.8$ & $171.2 \pm 142.5$ & $121.4 \pm 97.5$ & $10.8 \pm 18.7^{*}$ & $318.7 \pm 142.0$ & $219.9 \pm 151.2$ & $86.6 \pm 72.0$ & $12.3 \pm 17.2^{*}$ \\
\hline Married/cohabitate & 76 & 77.6 & $363.6 \pm 139.3$ & $215.3 \pm 132.4$ & $130.7 \pm 100.2$ & $17.7 \pm 19.9$ & $346.9 \pm 151.7$ & $231.5 \pm 153.9$ & $95.1 \pm 77.4$ & $20.3 \pm 21.4$ \\
\hline \multicolumn{11}{|l|}{ Professional status ${ }^{\dagger}, \mathrm{a}$} \\
\hline Employed/student & 81 & 82.7 & $345.5 \pm 150.8$ & $198.2 \pm 142.7$ & $131.7 \pm 100.0$ & $15.6 \pm 19.1$ & $344.9 \pm 154.4$ & $230.6 \pm 156.5$ & $96.2 \pm 77.8$ & $18.1 \pm 18.4$ \\
\hline Unemployed & 17 & 17.3 & $371.8 \pm 145.6$ & $239.7 \pm 97.2$ & $113.5 \pm 96.9$ & $18.6 \pm 23.0$ & $320.3 \pm 124.2$ & $220.9 \pm 136.7$ & $78.9 \pm 66.5$ & $20.4 \pm 30.0$ \\
\hline \multicolumn{11}{|l|}{ Monthly income $(€)^{\dagger, b}$} \\
\hline$<500$ & 25 & 25.5 & $343.3 \pm 195.8$ & $199.7 \pm 165.6$ & $130.6 \pm 114.6$ & $13.0 \pm 16.3$ & $352.9 \pm 180.4$ & $246.4 \pm 178.8$ & $92.0 \pm 65.3$ & $14.5 \pm 10.8^{*}$ \\
\hline $500-1250$ & 51 & 52.0 & $338.2 \pm 133.6$ & $205.7 \pm 124.6$ & $118.7 \pm 91.8$ & $14.1 \pm 16.6$ & $337.5 \pm 145.4$ & $226.1 \pm 141.2$ & $96.6 \pm 78.7$ & $14.7 \pm 18.4$ \\
\hline$\geq 1250$ & 22 & 22.4 & $384.7 \pm 123.4$ & $211.3 \pm 132.7$ & $149.1 \pm 98.3$ & $24.2 \pm 27.4$ & $333.8 \pm 121.5$ & $215.4 \pm 151.6$ & $86.5 \pm 83.2$ & $31.8 \pm 28.2$ \\
\hline \multicolumn{11}{|c|}{ Smoking during pregnancy } \\
\hline Yes & 15 & 15.3 & $354.8 \pm 126.9$ & $179.5 \pm 118.4$ & $163.1 \pm 102.6$ & $12.2 \pm 15.9$ & $287.7 \pm 131.7$ & $162.6 \pm 129.0$ & $112.7 \pm 62.6$ & $12.4 \pm 7.7$ \\
\hline No & 83 & 84.7 & $349.2 \pm 153.9$ & $210.1 \pm 139.5$ & $122.3 \pm 97.9$ & $16.8 \pm 20.4$ & $350.1 \pm 151.1$ & $240.9 \pm 154.1$ & $89.7 \pm 77.9$ & $19.6 \pm 22.1$ \\
\hline \multicolumn{11}{|l|}{ Parity a } \\
\hline Primiparous & 57 & 58.2 & $338.8 \pm 147.4$ & $201.7 \pm 131.3$ & $119.5 \pm 98.3$ & $17.6 \pm 22.7$ & $337.2 \pm 154.1$ & $221.7 \pm 152.1$ & $94.7 \pm 77.4$ & $20.8 \pm 21.8$ \\
\hline Multiparous & 41 & 41.8 & $365.8 \pm 152.7$ & $210.5 \pm 144.8$ & $141.2 \pm 100.2$ & $14.1 \pm 14.8$ & $345.3 \pm 144.3$ & $238.9 \pm 154.7$ & $91.1 \pm 74.7$ & $15.3 \pm 18.9$ \\
\hline \multicolumn{11}{|c|}{ Pre-pregnancy weight status ${ }^{\mathrm{a}}$} \\
\hline Non-overweight & 59 & 60.2 & $358.5 \pm 163.5$ & $206.8 \pm 147.4$ & $133.7 \pm 105.5$ & $17.9 \pm 21.1$ & $333.8 \pm 140.5$ & $220.5 \pm 142.0$ & $90.7 \pm 78.4$ & $22.7 \pm 21.3^{*}$ \\
\hline Overweight/Obese & 39 & 39.8 & $337.4 \pm 126.4$ & $203.2 \pm 119.7$ & $120.8 \pm 89.5$ & $13.4 \pm 17.4$ & $350.8 \pm 163.2$ & $241.9 \pm 168.4$ & $96.9 \pm 72.9$ & $12.0 \pm 18.2$ \\
\hline \multicolumn{11}{|c|}{ Gestational weight gain ${ }^{\mathrm{b}}$} \\
\hline Insufficient & 13 & 13.3 & $342.5 \pm 115.9$ & $224.1 \pm 143.5$ & $106.3 \pm 98.2$ & $12.2 \pm 11.5$ & $378.9 \pm 154.7$ & $280.7 \pm 162.3$ & $78.3 \pm 89.8$ & $19.9 \pm 22.3$ \\
\hline Adequate & 41 & 41.8 & $348.0 \pm 179.4$ & $210.5 \pm 144.8$ & $119.6 \pm 93.4$ & $18.0 \pm 20.0$ & $357.8 \pm 141.2$ & $248.3 \pm 129.9$ & $88.5 \pm 70.3$ & $21.0 \pm 21.3$ \\
\hline Excessive & 44 & 44.9 & $354.2 \pm 129.2$ & $195.2 \pm 128.4$ & $143.5 \pm 104.5$ & $15.5 \pm 21.6$ & $313.2 \pm 153.6$ & $195.6 \pm 164.9$ & $101.9 \pm 77.4$ & $15.7 \pm 19.7$ \\
\hline \multicolumn{11}{|c|}{ Mediterranean Diet adherence ${ }^{a}$} \\
\hline Low & $63 / 66^{\dagger}$ & $64.3 / 67.3^{\dagger}$ & $326.6 \pm 154.9^{*}$ & $191.7 \pm 140.4$ & $121.6 \pm 106.8$ & $13.3 \pm 17.8$ & $315.3 \pm 148.1^{*}$ & $204.4 \pm 153.0$ & $93.4 \pm 71.9$ & $17.5 \pm 20.7$ \\
\hline High & $35 / 32^{\dagger}$ & $35.7 / 32.7^{\dagger}$ & $492.3 \pm 130.8$ & $230.1 \pm 127.1$ & $141.1 \pm 83.7$ & $21.1 \pm 22.3$ & $392.8 \pm 140.0$ & $279.5 \pm 140.8$ & $92.8 \pm 84.8$ & $20.5 \pm 10.8$ \\
\hline \multicolumn{11}{|l|}{ Supplementation ${ }^{\mathrm{a}}$} \\
\hline Yes & $76 / 71^{\dagger}$ & $77.6 / 72.4$ & $361.2 \pm 149.1$ & $213.7 \pm 139.4$ & $131.4 \pm 104.3$ & $16.1 \pm 18.7$ & $325.7 \pm 146.7$ & $214.9 \pm 147.8$ & $91.4 \pm 76.5$ & $19.4 \pm 21.6$ \\
\hline No & $22 / 27^{\dagger}$ & $22.4 / 27.6$ & $311.7 \pm 147.8$ & $176.8 \pm 124.2$ & $118.8 \pm 80.5$ & $16.2 \pm 23.5$ & $379.7 \pm 151.9$ & $265.7 \pm 161.5$ & $97.8 \pm 75.7$ & $16.2 \pm 18.3$ \\
\hline
\end{tabular}

${ }^{*} P<0.05$.

$\dagger$ Values are to the first/second trimester, respectively.

$\S$ Values were natural log-transformed before analysis, but non-transformed values are presented in the table.

a Analysis by Student's $t$-test.

${ }^{b}$ Analysis by one-way analysis of variance. 
dairy, milk, and yogurt according to maternal sociodemographic and lifestyle characteristics.

Women who were supplemented during pregnancy $17.1 \%$ and $41.9 \%$ took iron, $84.1 \%$ and $75.7 \%$ took folic acid, 3.7\% and 5.4\% took calcium and $6.1 \%$ and $17.6 \%$ took multivitamins at the first and the second trimester, respectively (data not shown).

Neonatal and maternal outcomes according to maternal socio-demographic and lifestyle characteristics are presented in Table 2. No significant differences were seen in neonatal and maternal outcomes between maternal socio-demographic and lifestyle characteristics, except for weight gain during pregnancy. Additionally, no significant differences were seen in neonatal and maternal outcomes for supplementation (data not shown).

In the second trimester pregnant women had higher energy intake and lower calcium, iodine, and yogurt intake than in the first trimester $(P<0.05)$. Significant correlations were seen in all nutrients (except iron), dairy products, and Mediterranean score between the first and second trimesters $(P<0.05$, for all), ranging from 0.207 to 0.600 (Table 3).

The association between dairy product intake and neonatal and maternal outcomes are presented in Table 4. After adjusting for potential confounders, total dairy and yogurt intake in the first trimester were positively associated with head circumference and placental weight, respectively $(\beta=0.002, P=0.014, \beta=0.333, P=0.012$, respectively). Change in total dairy intake between the second and first trimester was negatively associated with maternal weight gain during pregnancy $(\beta=-0.007, P=0.020)$.

\section{Discussion}

This study suggests that neonatal and maternal outcomes are associated with dairy product intake during pregnancy. Particularly, total dairy and yogurt intake in the first trimester were positively associated respectively with head circumference and placental weight. Additionally, the change in total dairy intake between the second and first trimester was negatively associated with gestational weight gain. The associations identified were not confounded by dietary variables and other maternal characteristics.

In the past few years, it has been suggested that milk or dairy product intake are associated with higher gestational weight gain [22], placental weight $[23,24]$, and birth weight $[7,25,26]$. Furthermore, similarly to the present results a positive association between dairy product intake and head circumference has been reported in previous literature $[23-25,27]$. A prospective cohort study in 3405 mothers has found that maternal milk consumption of $>2-3$ glasses per day was associated with a $2.2 \mathrm{~mm}$ (95\% Cl: $0.2,4.2)$ larger head circumference at birth compared to mothers with a milk intake of 0-1 glasses per day [25]. Likewise, data from the Danish National Birth Cohort has showed that maternal milk product intake during midpregnancy was associated with an increased mean birth head circumference [23]. A positive association between head circumference and frequency of milk consumption at 18 week of gestation was also seen in a prospective study in India [24]. On the other hand, in a study that compared babies whose mothers restricted their milk intake during pregnancy with the babies of those who did not, no difference was found in head circumference [6]. Smaller head circumference has been linked to poorer verbal, visuospatial, and arithmetic abilities [28], early age at adiposity rebound [29], and higher risk of death from coronary heart disease later in life [30].

Regarding the mechanism underlying the effect of dairy product intake on neonatal outcomes studies have focused essentially on milk consumption. It is believed that the role of milk on fetal growth is due to the presence of biologically-active components. Milk consumption has been associated with increased serum levels of insulin-like growth factor-1 (IGF-1) [31], which in pregnant women regulates the placental transfer of nutrients to the fetus increasing secretion and bioavailability of fetal IGF-I and may promote fetal growth $[32,33]$. Some studies have shown positive associations between maternal IGF-1 and birth weight [34], and others had no associations with birth weight or other neonatal anthropometric indices [35-37]. However, to the best of our knowledge, no study has investigated the relationship between milk intake during pregnancy and maternal IGF-1 level on neonatal outcomes. Other milk components, such as protein, have also been positively associated with birth weight [23].

To the best of our knowledge, no study has investigated the relationship between yogurt consumption and placental weight. The majority of studies have investigated only milk consumption or dairy products as a whole. Olsen et al. [23] in their study pooled milk with yogurt consumption in one group, making it impossible to identify the isolate relationship of yogurt with placental weight. However, the latter found an increment of placental weight according to frequency of milk consumption during pregnancy. During dairy processing, a variety of biochemical changes in milk composition are 
Table 2 Neonatal and maternal outcomes according to maternal socio-demographic and lifestyle characteristics.

\begin{tabular}{|c|c|c|c|c|c|c|c|c|c|c|}
\hline & \multicolumn{8}{|c|}{ Neonatal outcomes } & \multicolumn{2}{|c|}{ Maternal outcome } \\
\hline & Birth weigth (g) & $P$ & Length $(\mathrm{cm})$ & $P$ & $\begin{array}{l}\text { Head } \\
\text { circumference } \\
(\mathrm{cm})\end{array}$ & $P$ & $\begin{array}{l}\text { Placental } \\
\text { weight (g) }\end{array}$ & $P$ & $\begin{array}{l}\text { Weight gain } \\
(\mathrm{kg})\end{array}$ & $P$ \\
\hline All & $3230.6 \pm 441.6$ & - & $49.1 \pm 2.0$ & - & $34.1 \pm 1.3$ & - & $601.8 \pm 124.2$ & - & $14.5 \pm 5.0$ & \\
\hline \multicolumn{11}{|l|}{ Age $\left(\right.$ years) ${ }^{\mathrm{a}}$} \\
\hline $18-30$ & $3227.7 \pm 407.8$ & 0.952 & $49.3 \pm 1.9$ & 0.617 & $34.1 \pm 1.2$ & 0.765 & $591.8 \pm 121.5$ & 0.465 & $15.1 \pm 4.3$ & 0.248 \\
\hline $31-40$ & $3233.2 \pm 473.4$ & & $49.0 \pm 2.1$ & & $34.1 \pm 1.5$ & & $611.2 \pm 127.2$ & & $13.9 \pm 5.6$ & \\
\hline \multicolumn{11}{|c|}{ Smoking during pregnancy } \\
\hline Yes & $3273.7 \pm 461.6$ & 0.684 & $49.0 \pm 1.9$ & 0.710 & $33.8 \pm 1.4$ & 0.348 & $638, .2 \pm 161.3$ & 0.234 & $15.7 \pm 4.4$ & 0.304 \\
\hline No & $3222.8 \pm 440.3$ & & $49.2 \pm 2.0$ & & $34.2 \pm 1.3$ & & $595.0 \pm 116.1$ & & $14.3 \pm 5.1$ & \\
\hline \multicolumn{11}{|l|}{ Parity $^{a}$} \\
\hline Primiparous & $3198.2 \pm 442.8$ & 0.395 & $49.1 \pm 2.0$ & 0.747 & $34.0 \pm 1.3$ & 0.379 & $587.9 \pm 124.8$ & 0.224 & $14.6 \pm 4.5$ & 0.874 \\
\hline Multiparous & $3275.6 \pm 441.4$ & & $49.2 \pm 1.9$ & & $34.2 \pm 1.4$ & & $620.5 \pm 122.5$ & & $14.4 \pm 5.8$ & \\
\hline \multicolumn{11}{|c|}{ Pre-pregnancy weight status ${ }^{\mathrm{a}}$} \\
\hline Non-overweight & $3244.9 \pm 443.5$ & 0.695 & $49.4 \pm 2.1$ & 0.191 & $34.3 \pm 1.4$ & 0.087 & $601.4 \pm 107.7$ & 0.972 & $15.2 \pm 4.9$ & 0.078 \\
\hline Overweight/Obese & $3209.0 \pm 443.3$ & & $48.8 \pm 1.8$ & & $33.8 \pm 1.3$ & & $602.4 \pm 145.8$ & & $13.4 \pm 5.1$ & \\
\hline \multicolumn{11}{|c|}{ Gestational weight gain ${ }^{\mathrm{b}}$} \\
\hline Insufficient & $3164.2 \pm 589.7$ & 0.734 & $49.2 \pm 2.1$ & 0.748 & $33.9 \pm 2.0$ & 0.757 & $631.4 \pm 87.5$ & 0.606 & $9.1 \pm 4.5$ & $<0.00$ \\
\hline Adequate & $3214.0 \pm 353.7$ & & $49.3 \pm 1.5$ & & $34.1 \pm 1.1$ & & $588.9 \pm 117.2$ & & $12.7 \pm 2.9$ & \\
\hline Excessive & $3265.7 \pm 472.8$ & & $49.0 \pm 2.3$ & & $34.2 \pm 1.3$ & & $606.1 \pm 137.7$ & & $17.7 \pm 4.6$ & \\
\hline \multicolumn{11}{|c|}{ Mediterranean Diet adherence ${ }^{a}$} \\
\hline \multicolumn{11}{|c|}{ First trimester } \\
\hline Low & $3232.5 \pm 425.5$ & 0.956 & $49.0 \pm 1.7$ & 0.266 & $34.1 \pm 1.3$ & 0.706 & $597.2 \pm 124.9$ & 0.634 & $14.4 \pm 5.4$ & 0.933 \\
\hline High & $3227.3 \pm 475.6$ & & $49.4 \pm 2.4$ & & $34.2 \pm 1.5$ & & $610.5 \pm 124.3$ & & $14.5 \pm 4.5$ & \\
\hline \multicolumn{11}{|l|}{ Second trimester } \\
\hline Low & $3222.1 \pm 425.2$ & 0.784 & $49.0 \pm 1.9$ & 0.236 & $34.1 \pm 1.3$ & 0.869 & $599.7 \pm 119.4$ & 0.825 & $14.4 \pm 5.1$ & 0.839 \\
\hline High & $3248.28 \pm 480.1$ & & $49.5 \pm 2.2$ & & $34.1 \pm 1.4$ & & $605.8 \pm 134.7$ & & $14.6 \pm 5.0$ & \\
\hline
\end{tabular}

Data are all mean \pm standard deviation.

a Analysis by Student's $t$-test.

b Analysis by one-way analysis of variance. 
Table 3 Nutritional and dietary intake according to trimesters.

\begin{tabular}{|c|c|c|c|c|c|}
\hline & $\begin{array}{l}\text { First trimester }^{a} \\
(n=98)\end{array}$ & $\begin{array}{l}\text { Second trimester }{ }^{a} \\
(n=98)\end{array}$ & $\begin{array}{l}\text { Mean of differences }{ }^{\dagger} \\
(95 \% \mathrm{Cl})\end{array}$ & $P^{b}$ & $\begin{array}{l}\text { Pairwise } \\
\text { correlation }\end{array}$ \\
\hline \multicolumn{6}{|l|}{ Nutrients } \\
\hline Energy (kcal/d) & $1717.5 \pm 405.4$ & $1907.8 \pm 457.0$ & $190.3(286.6,94.0)$ & $<0.001$ & $0.384^{* *}$ \\
\hline Protein (\% TEI) & $19.8 \pm 3.0$ & $19.3 \pm 3.8$ & $-0.46(-1.3,0.39)$ & 0.286 & $0.235^{*}$ \\
\hline Carbohydrates (\% TEI) & $48.5 \pm 5.5$ & $48.3 \pm 5.8$ & $-0.21(-1.5,1.1)$ & 0.746 & $0.345^{*}$ \\
\hline Total fat (\% TEI) & $31.7 \pm 5.2$ & $32.3 \pm 5.8$ & $0.62(-0.76,2.0)$ & 0.375 & $0.225^{*}$ \\
\hline SFA (\% TEI) & $10.2 \pm 2.3$ & $9.8 \pm 2.2$ & $-0.40(-0.97,0.17)$ & 0.162 & $0.208^{*}$ \\
\hline MUFA (\% TEI) & $11.4 \pm 2.6$ & $11.7 \pm 3.9$ & $0.30(-0.54,1.1)$ & 0.483 & $0.207^{*}$ \\
\hline PUFA (\% TEI) & $4.3 \pm 1.3$ & $4.6 \pm 1.2$ & $0.26(-0.05,0.57)$ & 0.104 & $0.227^{*}$ \\
\hline Dietary fiber (g/1000kcal) & $8.2 \pm 3.0$ & $8.6 \pm 3.0$ & $0.40(-0.23,1.02)$ & 0.215 & $0.460^{* *}$ \\
\hline Folate $(\mu \mathrm{g} / \mathrm{d})^{\S}$ & $273.1 .0 \pm 140.0$ & $285.3 \pm 137.3$ & $12.2(-22.6,47.0)$ & 0.488 & $0.217^{*}$ \\
\hline Calcium $(\mathrm{mg} / \mathrm{d})^{\S}$ & $837.5 \pm 291.6$ & $779.4 \pm 251.8$ & $-58.2(-109.1,-7.3)$ & 0.026 & $0.572^{* *}$ \\
\hline lodine $(\mu \mathrm{g} / \mathrm{d})^{\S}$ & $104.8 \pm 43.4$ & $90.5 \pm 40.5$ & $-14.3(-22.6,-5.9)$ & 0.001 & $0.506^{* * *}$ \\
\hline Iron $(\mathrm{mg} / \mathrm{d})^{\S}$ & $10.1 \pm 4.2$ & $11.1 \pm 4.1$ & $1.0(0.53,-0.04)$ & 0.059 & 0.191 \\
\hline \multicolumn{6}{|l|}{ Food groups } \\
\hline Dairy products (g/d) & $350.1 \pm 149.5$ & $340.6 \pm 228.9$ & $-9.5(-41.6,22.5)$ & 0.558 & $0.428^{* * *}$ \\
\hline Milk (g/d) & $205.4 \pm 136.4$ & $228.9 \pm 152.6$ & $23.5(-2.6,49.6)$ & 0.077 & $0.600^{* * *}$ \\
\hline Yogurt (g/d) & $128.6 \pm 99.2$ & $93.2 \pm 75.9$ & $-35.4(-54.5,-16.3)$ & $<0.001$ & $0.434^{* *}$ \\
\hline Cheese (g/d) & $16.1 \pm 19.8$ & $18.5 \pm 20.7$ & $2.4(-1.7,6.5)$ & 0.250 & $0.493^{* *}$ \\
\hline Mediterranean Diet score & $3.9 \pm 1.6$ & $4.0 \pm 1.5$ & $0.04(-0.30,0.38)$ & 0.814 & $0.359^{* *}$ \\
\hline $\begin{array}{l}\text { MUFA, monounsaturated fatty ac } \\
\text { a Data are all mean } \pm \text { standar } \\
\text { b Analysis by paired } t \text {-test } \\
{ }^{*} P<0.05 \text {. } \\
{ }^{* *} P<0.001 \text {. } \\
\text { § From dietary source only. } \\
{ }^{\dagger} \text { Differences between the sec }\end{array}$ & $\begin{array}{l}\text { cids; PUFA, polyunsa } \\
\text { d deviation. }\end{array}$ & aturated fatty acid; TE & I, total energy intake; SFA, & saturate & tty acids. \\
\hline
\end{tabular}

generated, including the loss of more labile constituents (e.g., vitamin C, enzymes), the removal of bioactive components (e.g., whey removal from cheese), and/or the addition of ingredients (e.g., the addition of sugar to yogurt and salt to cheese) [38]. Moreover, there is a large amount of yogurts on the market that vary in microorganism culture, fat, and sugar content. A randomised controlled clinical trial among pregnant women found that, compared to conventional yogurt, daily consumption of probiotic yogurt during 9 weeks maintains serum insulin levels and might prevent the development of insulin resistance, which is related to adverse pregnancy outcomes [39].

In this study, we also found that an increase in total dairy product intake between the first and the second trimesters was negatively associated with maternal weight gain. This is an interesting finding in view of the fact that some women may restrict their dairy product consumption to avoid excessive weight gain [40]. It has been described that increased dairy consumption is associated with both weight loss and weight gain [41]. In contrast to the present findings, Olafsdotti et al. [22] found that women who had eaten more sweets early in pregnancy and consumed more milk in late pregnancy had increased risk of gaining excessive weight. Likewise, another study found a positive association between dairy consumption during pregnancy and excessive gestational weight gain, but the results are only slightly significant (Odds ratio $=1.09 \mathrm{Cl}$ 95\%: 1.01, 1.19) [42].

However, due to both the heterogeneity among exposure and the differences in sample and effect size between studies, the role played by dairy product consumption during pregnancy still remains controversial. Moreover, the majority of studies cover all pregnancies or only one moment during pregnancy (early or late pregnancy). It is well known that dietary changes over the course of a pregnancy may occur and may affect pregnancy outcomes $[22,43]$. Thus, it is important to consider dietary change in all pregnancies as well as isolate trimesters, since consumption at different times may have different effects on neonatal and maternal outcomes.

Some limitations of the present study should be addressed. The low number of participants may have limited us from identifying small effects when disaggregating dairy products. On the other hand, the majority of the analyses have a power $\geq 80 \%$, which avoids Type II error. Moreover, although 
Table 4 Regression analysis of the association between neonatal outcomes and dietary intake during the first and second trimester, and changes occurred between trimesters.

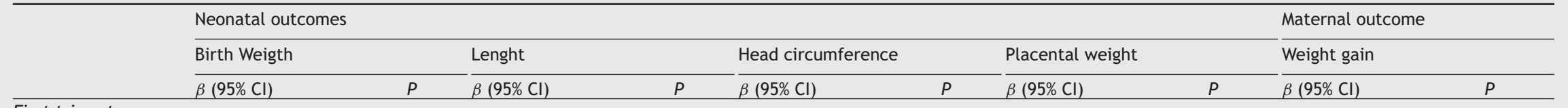

First trimester

$\begin{array}{llllllllllll}\text { Dairy products (g/d) } & 0.259(-0.285,0.804) & 0.347 & 0.001(-0.002,0.003) & 0.494 & 0.002(0.0004,0.004) & 0.014 & 0.140(-0.041,0.321) & 0.128 & 0.003(-0.004,0.010) & 0.411\end{array}$

Yogurt $(\mathrm{g} / \mathrm{d})$

$-0.014(-0.596,0.569) \quad 0.962-0.001(-0.003,0.002) \quad 0.586$

$0.002(-0.001,0.003) \quad 0.192-0.009(-0.204,0.186)$

$0.928 \quad 0.000(-0.008,0.007) \quad 0.945$

heese $(\mathrm{g} / \mathrm{d})$

$\begin{array}{cccc}0.588(-0.194,1.369) & 0.139 & 0.003(-0.001,0.007) & 0.106 \\ -0.529(-4.596,3.539) & 0.797 & 0.006(-0.013,0.025) & 0.529\end{array}$

$0.004(-0.009,0.017) \quad 0.518$

$0.438(-1.812,0.937)$

$0.012 \quad 0.007(-0.003,0.017)$

0.189
0.851

Second trimester

Dairy products $(\mathrm{g} / \mathrm{d})$

Milk (g/d)

$0.162(-0.394,0.718) \quad 0.565$

$0.000(-0.002,0.003) \quad 0.921$

$0.004(-0.009,0.017) \quad 0.518$

$-0.092(-0.645,0.461) \quad 0.741$

Yogurt (g/d)

$0.948(-0.069,1.965) \quad 0.067$

$-0.001(-0.004,0.001) \quad 0.337$

$0.001(-0.001,0.003) \quad 0.203$

Cheese $(\mathrm{g} / \mathrm{d})$

$-0.937(-4.860,2.986) \quad 0.636$

$0.004(0.000,0.009) \quad 0.064$

$\begin{array}{lll}(-0.001,0.002) & 0.533 & 0.005(-0.173,0.183)\end{array}$

$0.528-0.005(-0.058,0.048)$

Dairy products $(\mathrm{g} / \mathrm{d})$

Milk (g/d)

$-0.142(-0.636,0.352) \quad 0.569-0.001(-0.003,0.002) \quad 0.529-0.1$

0.219

$0.0 .058+0.0 .178$

Yogurt $(g / d)$ $-0.078(-0.907,0.751) \quad 0.620-0.001(-0.004,0.002) \quad 0.550$

$0.001(-0.002,0.001) \quad 0.293-0.070(-0.233,0.094) \quad 0.400-0.007(-0.014,-0.001) \quad 0.020$

$\begin{array}{llllllllllllll}\text { Cheese }(\mathrm{g} / \mathrm{d}) \quad-0.819(-4.673,3.034) & 0.674 & -0.002 & -0.020,0.016) & 0.841 & -0.001 & (-0.004,0.002) & 0.468 & -0.257 & (-0.542,0.028) & 0.076 & -0.008 & (-0.018,0.003) & 0.159\end{array}$

Regression model was adjusted for energy intake (according to the trimester; the model with the change of dairy intake includes the mean of the trimesters), weight gain during pregnancy, neonatal sex, gestational weeks and Mediterranean diet score (according to the trimester; the model with the change of dairy intake includes the mean of the trimesters). For weight gain, model was adjusted for energy intake (according to the trimester; the model with the change of dairy intake includes the mean of the trimesters), pre-pregnancy body mass index, neonatal sex, gestational weeks and Mediterranean diet score (according to the trimester; the model with the change of dairy intake includes the mean of the trimesters). Change in dairy products intake during pregnancy occurred between the second and first trimester; $\mathrm{Cl}$, confidence interval. 
oral and written instructions were given asking women to not change their dietary habits during the completion of the food diary, changes may have occurred in habitual eating patterns, and there may have been omission of less socially acceptable dietary habits [44].

\section{Conclusion}

In summary, the present findings suggest that dairy product intake during pregnancy would, perhaps, have an effect on neonatal head circumference, placental weight, and gestational weight gain. Evidence from published studies is limited and the health-related mechanisms of dairy product consumption are still not well understood. Thus, further studies are needed to understand the role of dairy intake during pregnancy on adequate fetal growth and maternal health, and the underlying mechanisms.

\section{Declaration of interest statement}

The authors declare that they have no conflict of interests.

\section{Acknowledgements}

This project was funded by Fundação para a Ciência e Tecnologia (FCT) grants PTDC/DES/116586/201. The Research Centre on Physical Activity Health and Leisure (CIAFEL) is supported by UID/DTP/00617/2013.

We greatly appreciate the cooperation health professionals for valuable support during data collection and all the pregnant women who agreed to voluntarily participate in this study.

\section{References}

[1] Williamson CS. Nutrition in pregnancy. Nutr Bull 2006;31:28-59.

[2] Thompson JM, Wall C, Becroft DM, Robinson E, Wild CJ, Mitchell EA. Maternal dietary patterns in pregnancy and the association with small-for-gestational-age infants. Br J Nutr 2010;103(11 (June)):1665-73.

[3] Rodriguez-Bernal CL, Rebagliato M, Iniguez C, Vioque J, Navarrete-Munoz EM, Murcia M, et al. Diet quality in early pregnancy and its effects on fetal growth outcomes: the Infancia y Medio Ambiente (Childhood and Environment) Mother and Child Cohort Study in Spain. Am J Clin Nutr 2010;91(6 (June)):1659-66.
[4] Mikkelsen TB, Osterdal ML, Knudsen VK, Haugen M, Meltzer HM, Bakketeig L, et al. Association between a Mediterranean-type diet and risk of preterm birth among Danish women: a prospective cohort study. Acta Obstet Gynecol Scand 2008;87(3):325-30.

[5] Potdar RD, Sahariah SA, Gandhi M, Kehoe SH, Brown N, Sane H, et al. Improving women's diet quality preconceptionally and during gestation: effects on birth weight and prevalence of low birth weight - a randomized controlled efficacy trial in India (Mumbai Maternal Nutrition Project). Am J Clin Nutr 2014;100(5 (November)):1257-68.

[6] Mannion CA, Gray-Donald K, Koski KG. Association of low intake of milk and vitamin $D$ during pregnancy with decreased birth weight. CMAJ 2006;174(9 (April)):1273-7.

[7] Melnik BC, John S, Schmitz G. Milk consumption during pregnancy increases birth weight, a risk factor for the development of diseases of civilization. J Transl Med 2015;13(1 (January)):13.

[8] Brantsaeter AL, Olafsdottir AS, Forsum E, Olsen SF, Thorsdottir I. Does milk and dairy consumption during pregnancy influence fetal growth and infant birthweight? A systematic literature review. Food Nutr Res 2012:56.

[9] Miyake Y, Tanaka K, Okubo H, Sasaki S, Arakawa M. Maternal consumption of dairy products, calcium, and vitamin D during pregnancy and infantile allergic disorders. Ann Allergy Asthma Immunology 2014;113(1 (July)):82-7.

[10] Godfrey KM, Barker DJ. Fetal programming and adult health. Public Health Nutr 2001;4(2B (April)):611-24.

[11] Osler M, Lund R, Kriegbaum M, Andersen AM. The influence of birth weight and body mass in early adulthood on early coronary heart disease risk among Danish men born in 1953. Eur J Epidemiol 2009;24(1):57-61.

[12] Pietilainen KH, Kaprio J, Rasanen M, Winter T, Rissanen A, Rose RJ. Tracking of body size from birth to late adolescence: contributions of birth length, birth weight, duration of gestation, parents' body size, and twinship. Am J Epidemiol 2001;154(1 (July)):21-9.

[13] Samaras TT, Elrick H, Storms LH. Birthweight, rapid growth, cancer, and longevity: a review. J Natl Med Assoc 2003;95(12 (December)):1170-83.

[14] Hutcheon JA, McNamara H, Platt RW, Benjamin A, Kramer MS. Placental weight for gestational age and adverse perinatal outcomes. Obstet Gynecol 2012;119(6 (June)):1251-8.

[15] Siega-Riz AM, Viswanathan M, Moos MK, Deierlein A, Mumford S, Knaack J, et al. A systematic review of outcomes of maternal weight gain according to the Institute of Medicine recommendations: birthweight, fetal growth, and postpartum weight retention. Am J Obstet Gynecol 2009;201(4 (October)):339, e1-14.

[16] Santos PC, Abreu S, Moreira C, Lopes D, Santos R, Alves $O$, et al. Impact of compliance with different guidelines on physical activity during pregnancy and perceived barriers to leisure physical activity. J Sports Sci 2014;32(14):1398-408.

[17] Institute of Medicine. National Research Council: weight gain during pregnancy: reexamining the guidelines. Washington, DC: The National Academies Press; 2009.

[18] Huijbregts P, Feskens E, Rasanen L, Fidanza F, Nissinen A, Menotti A, et al. Dietary pattern and 20 year mortality in elderly men in Finland, Italy, and The Netherlands: longitudinal cohort study. BMJ 1997;315(7099 (July)):13-7.

[19] Trichopoulou A, Kouris-Blazos A, Wahlqvist ML, GnardelLis C, Lagiou P, Polychronopoulos E, et al. Diet and overall survival in elderly people. BMJ 1995;311(7018 (December)):1457-60.

[20] Chatzi L, Mendez M, Garcia R, Roumeliotaki T, Ibarluzea J, Tardon A, et al. Inma, groups Rs: Mediterranean diet 
adherence during pregnancy and fetal growth: INMA (Spain) and RHEA (Greece) mother-child cohort studies. Br J Nutr 2012;107(1 (January)):135-45.

[21] World Health Organization. Obesity: preventing and managing the global epidemic. Report of the WHO consultation. Geneva: World Health Organization; 2000.

[22] Olafsdottir AS, Skuladottir GV, Thorsdottir I, Hauksson A, Steingrimsdottir L. Maternal diet in early and late pregnancy in relation to weight gain. Int J Obes (Lond) 2006;30(3 (March)):492-9.

[23] Olsen SF, Halldorsson TI, Willett WC, Knudsen VK, Gillman MW, Mikkelsen TB, et al. Milk consumption during pregnancy is associated with increased infant size at birth: prospective cohort study. Am J Clin Nutr 2007;86(4 (October)):1104-10.

[24] Rao S, Yajnik CS, Kanade A, Fall CH, Margetts BM, Jackson AA, et al. Intake of micronutrient-rich foods in rural Indian mothers is associated with the size of their babies at birth: Pune Maternal Nutrition Study. J Nutr 2001;131(4 (April)):1217-24.

[25] Heppe DH, van Dam RM, Willemsen SP, den Breeijen H, Raat H, Hofman A, et al. Maternal milk consumption, fetal growth, and the risks of neonatal complications: the Generation R Study. Am J Clin Nutr 2011;94(2 (August)):501-9.

[26] Ludvigsson JF, Ludvigsson J. Milk consumption during pregnancy and infant birthweight. Acta Paediatr 2004;93(11 (November)):1474-8.

[27] Borazjani F, Angali KA, Kulkarni SS: Milk. Protein intake by pregnant women affects growth of foetus. J Health Popul Nutr 2013;31(4 (December)):435-45.

[28] Raikkonen K, Forsen T, Henriksson M, Kajantie E, Heinonen K, Pesonen AK, et al. Growth trajectories and intellectual abilities in young adulthood. Am J Epidemiol 2009;170(4 (August)):447-55.

[29] Eriksson JG, Kajantie E, Lampl M, Osmond C, Barker DJP. Small head circumference at birth and early age at adiposity rebound. Acta Physiol 2014;210(1 (January)):154-60.

[30] Risnes KR, Nilsen TIL, Romundstad PR, Vatten LJ. Head size at birth and long-term mortality from coronary heart disease. Int J Epidemiol 2009;38(4 (August)):955-62.

[31] Qin LQ, He K, Xu JY. Milk consumption and circulating insulin-like growth factor-I level: a systematic literature review. Int J Food Sci Nutr 2009;60:330-40.

[32] Caufriez A, Frankenne F, Hennen G, Copinschi G. Regulation of maternal insulin-like growth-factor-I by placental growth-hormone in pregnancy - possible action of maternal Igf-I on fetal growth. Horm Res 1994;42(1-2):62-5.

[33] Yang SW, Yu JS. Relationship of insulin-like growth factorI, insulin-like growth factor binding protein-3, insulin, growth hormone in cord blood and maternal factors with birth height and birthweight. Pediatr Int 2000;42(1 (February)):31-6.

[34] Boyne MS, Thame M, Bennett FI, Osmond C, Miell JP, Forrester TE. The relationship among circulating insulin-like growth factor (IGF)-I, IGF-binding proteins-1 and-2, and birth anthropometry: a prospective study. J Clin Endocr Metab 2003;88(4 (April)):1687-91.

[35] Pathmaperuma AN, Tennekoon KH, Senanayake L, Karunanayake EH. Maternal and cord blood levels of insulin-like growth factors-I and -II and insulin-like growth factor binding protein-1: correlation with birth weight and maternal anthropometric indices. Ceylon Med J 2007;52(2 (June)):48-52.

[36] Holmes RP, Holly JM, Soothill PW. A prospective study of maternal serum insulin-like growth factor-I in pregnancies with appropriately grown or growth restricted fetuses. $\mathrm{Br} \mathrm{J}$ Obstet Gynaecol 1998;105(12 (December)):1273-8.

[37] Orbak Z, Darcan S, Coker M, Goksen D. Maternal and fetal serum insulin-like growth factor-I (IGF-I) IGF binding protein-3 (IGFBP-3), leptin levels and early postnatal growth in infants born asymmetrically small for gestational age. J Pediatr Endocrinol Metab 2001;14(8 (September-October)):1119-27.

[38] Wiley AS. Dairy and milk consumption and child growth: Is BMI involved? An analysis of NHANES 1999-2004. Am J Hum Biol 2010;22(4 (July-August)):517-25.

[39] Asemi Z, Samimi M, Tabassi Z, Naghibi Rad M, Rahimi Foroushani A, Khorammian H, et al. Effect of daily consumption of probiotic yoghurt on insulin resistance in pregnant women: a randomized controlled trial. Eur J Clin Nutr 2013;67(1 (January)):71-4.

[40] Gulliver P, Horwath CC. Assessing women's perceived benefits, barriers, and stage of change for meeting milk product consumption recommendations. J Am Diet Assoc 2001;101(11 (November)):1354-7.

[41] Chen M, Pan A, Malik VS, Hu FB. Effects of dairy intake on body weight and fat: a meta-analysis of randomized controlled trials. Am J Clin Nutr 2012;96(4 (October)):735-47.

[42] Stuebe AM, Oken E, Gillman MW. Associations of diet and physical activity during pregnancy with risk for excessive gestational weight gain. Am J Obstet Gynecol 2009;201(1 (July)):58, e51-8.

[43] Rifas-Shiman SL, Rich-Edwards JW, Willett WC, Kleinman KP, Oken E, Gillman MW. Changes in dietary intake from the first to the second trimester of pregnancy. Paediatr Perinat Epidemiol 2006;20(1 (January)):35-42.

[44] Biro G, Hulshof KFAM, Ovesen L, Cruz JA, Grp E. Selection of methodology to assess food intake. Eur J Clin Nutr 2002;56 (May):S25-32.

Available online at www.sciencedirect.com

\section{ScienceDirect}

